University of Nebraska - Lincoln

DigitalCommons@University of Nebraska - Lincoln

Insect Fragments in Flour: Relationship to Lesser Grain Borer (Coleoptera: Bostrichidae) Infestation Level in Wheat and Rapid Detection Using Near-Infrared Spectroscopy

\author{
Joel Perez-Mendoza \\ Montana State University \\ James E. Throne \\ USDA-ARS, Manhattan, KS, james.throne@ars.usda.gov \\ Elizabeth B. Maghirang \\ USDA-ARS
}

Floyd E. Dowell

USDA-ARS

James E. Baker

USDA-ARS

Follow this and additional works at: https://digitalcommons.unl.edu/usdaarsfacpub

\footnotetext{
Perez-Mendoza, Joel; Throne, James E.; Maghirang, Elizabeth B.; Dowell, Floyd E.; and Baker, James E., "Insect Fragments in Flour: Relationship to Lesser Grain Borer (Coleoptera: Bostrichidae) Infestation Level in Wheat and Rapid Detection Using Near-Infrared Spectroscopy" (2005). Publications from USDA-ARS / UNL Faculty. 2018.
}

https://digitalcommons.unl.edu/usdaarsfacpub/2018

This Article is brought to you for free and open access by the U.S. Department of Agriculture: Agricultural Research Service, Lincoln, Nebraska at DigitalCommons@University of Nebraska - Lincoln. It has been accepted for inclusion in Publications from USDA-ARS / UNL Faculty by an authorized administrator of DigitalCommons@University of Nebraska - Lincoln. 


\title{
Insect Fragments in Flour: Relationship to Lesser Grain Borer (Coleoptera: Bostrichidae) Infestation Level in Wheat and Rapid Detection Using Near-Infrared Spectroscopy
}

\author{
JOEL PEREZ-MENDOZA, ${ }^{1}$ JAMES E. THRONE, ${ }^{2}$ ELIZABETH B. MAGHIRANG, ${ }^{2}$ \\ FLOYD E. DOWELL, ${ }^{2}$ AND JAMES E. BAKER ${ }^{2}$
}

J. Econ. Entomol. 98(6): 2282-2291 (2005)

\begin{abstract}
We determined that the number of insect fragments, quantified using the standard flotation method, in flour milled from wheat infested with larvae, pupae, or preemergent adults of the lesser grain borer, Rhyzopertha dominica (F.), was proportional to infestation level. Wheat infested with a single preemergent adult contributed 28 and $10 \times$ as many fragments as wheat infested with a single larva or pupa, respectively. Using regression models that were developed from these data, we predicted that the maximum infestation level that would result in flour with fragment counts below the Food and Drug Administration defect action level (75 fragments / $50 \mathrm{~g}$ of flour) was 0.95 and $1.5 \%$ (380-640 infested kernels/ $\mathrm{kg}$ of wheat) for pupae and larvae, but it decreased to $0.05 \%$ (20 infested kernels $/ \mathrm{kg}$ ) when the grain was infested with preemergent adults. We also reexamined the accuracy and sensitivity of near-infrared spectroscopy (NIRS) for detecting insect fragments in flour by testing three different NIR spectrometers. NIRS-predicted numbers of insect fragments were correlated with the actual number of fragments. NIRS is less precise than the standard flotation method, but it is rapid, nondestructive, does not require extensive sample preparation, and could easily be automated for a more sophisticated sampling protocol for flour based on prescreening samples with NIRS followed up by use of the standard flotation method when necessary.
\end{abstract}

KEY WORDS Rhyzopertha dominica, stored products, flour, insect fragments, near-infrared spectroscopy

The Food And Drug Administration (FDA) has established a defect action level (DAL) of 75 insect fragments per $50 \mathrm{~g}$ of flour as the regulatory standard for quality control (FDA 1997). The presence of live insects is considered an adulteration if found in stored bulk grains by the FDA. Excessive insect feeding damage in grain may indicate that the grain has been stored under poor sanitary conditions, and the grain may be classified as adulterated and unfit for human or animal consumption. For example, if $>32$ insect-damaged kernels (IDKs) are found per $100 \mathrm{~g}$ of wheat, the wheat is classified as sample grade (FGIS 1999). IDK is caused by the emergence hole that internal adult insects leave when they emerge from infested kernels. Most U.S. grain mills use the IDK method to determine insect contamination of grain and to predict presence of insect fragments in flour milled from that grain. However, this visual inspection method does not cor-

Mention of trade names or commercial products in this publication is solely for the purpose of providing specific information and does not imply recommendation or endorsement by Montana State University or the USDA.

${ }^{1}$ Department of Entomology, Montana State University, Bozeman, MT 59717.

2 USDA-ARS Grain Marketing and Production Research Center, 1515 College Ave., Manhattan KS 66502. relate with actual insect infestation levels or with the number of insect fragments that are produced in flour milled from that grain (Wingfield and Pedersen 1985), mainly because it does not detect hidden insect infestation in wheat (Brader et al. 2002, Perez-Mendoza et al. 2004). Therefore, millers cannot rely on wheat grade standards or the number of IDKs as absolute predictors of the number of insect fragments that will be found in the flour. Instead, the number of insect fragments present in wheat flour depends more on the percentage of internal insect infestations in the grain before milling (Sachdeva 1978, Brader 1997).

The lesser grain borer, Rhyzopertha dominica (F.), is a common and destructive pest of stored wheat in the United States (Hagstrum et al. 1994). This pest that develops and feeds inside grain kernels is the main source of insect fragments in wheat flour (Pedersen 1992). Eggs are laid on the surface of grain kernels, and after hatching, the first instars bore into the grain (Elek 1994). Larvae pupate inside the kernels, and adults remain inside the kernels for several days after eclosion (Hagstrum and Flinn 1994). We refer to these newly eclosed adults still in the kernel as preemergent adults.

Immature stages and preemergent adults of internal grain feeding insects are not removed from the grain 
Table 1. Mean \pm SEM $(n=5)$ number of insect fragments recovered in flour from wheat samples $(100 \mathrm{~g})$ infested with three stages and different infestation levels of $R$. dominica

\begin{tabular}{|c|c|c|c|c|c|c|c|c|}
\hline \multicolumn{3}{|c|}{ Larvae } & \multicolumn{3}{|c|}{ Pupae } & \multicolumn{3}{|c|}{ Preemergent adults ${ }^{a}$} \\
\hline $\begin{array}{c}\% \\
\text { infestation }\end{array}$ & $\begin{array}{c}\text { No. of infested } \\
\text { kernels/100 g }\end{array}$ & $\begin{array}{l}\text { Fragment } \\
\text { counts }\end{array}$ & $\begin{array}{c}\% \\
\text { infestation }\end{array}$ & $\begin{array}{c}\text { No. of infested } \\
\text { kernels/100 g }\end{array}$ & $\begin{array}{c}\text { Fragment } \\
\text { counts }\end{array}$ & $\begin{array}{c}\% \\
\text { infestation }\end{array}$ & $\begin{array}{c}\text { No. of infested } \\
\text { kernels/100 g }\end{array}$ & $\begin{array}{l}\text { Fragment } \\
\text { counts }\end{array}$ \\
\hline 0 & 0 & $0 \pm 0$ & 0 & 0 & $0 \pm 0$ & 0 & 0 & $0 \pm 0$ \\
\hline 0.25 & 10 & $8.6 \pm 1.1$ & 0.125 & 5 & $10.6 \pm 1.0$ & 0.025 & 1 & $14.0 \pm 1.6$ \\
\hline 0.50 & 20 & $12.0 \pm 1.8$ & 0.250 & 10 & $17.6 \pm 2.0$ & 0.050 & 2 & $38.2 \pm 2.4$ \\
\hline 1.00 & 40 & $28.8 \pm 2.8$ & 0.375 & 15 & $25.4 \pm 3.9$ & 0.075 & 3 & $65.8 \pm 4.9$ \\
\hline 1.50 & 60 & $66.8 \pm 3.6$ & 0.500 & 20 & $37.6 \pm 2.2$ & 0.100 & 4 & $94.6 \pm 6.4$ \\
\hline 2.00 & 80 & $78.8 \pm 7.7$ & 0.750 & 30 & $50.2 \pm 3.8$ & 0.125 & 5 & $135.4 \pm 6.0$ \\
\hline 2.50 & 100 & $110.0 \pm 8.5$ & 1.000 & 40 & $71.8 \pm 7.3$ & 0.150 & 6 & $167.4 \pm 5.8$ \\
\hline 3.00 & 120 & $126.2 \pm 9.7$ & 1.250 & 50 & $97.8 \pm 7.3$ & 0.175 & 7 & $201.2 \pm 3.9$ \\
\hline 3.50 & 140 & $144.2 \pm 6.2$ & 1.500 & 60 & $100.6 \pm 3.7$ & 0.200 & 8 & $225.4 \pm 11.0$ \\
\hline 4.00 & 160 & $178.0 \pm 8.3$ & 1.750 & 70 & $131.6 \pm 8.7$ & 0.225 & 9 & $276.8 \pm 8.5$ \\
\hline
\end{tabular}

${ }^{a}$ Inside wheat kernels.

by ordinary grain cleaning machinery used before milling. As a result, these stages are the main source of insect fragments in wheat flour (Brader et al. 2002). However, the relationship between the initial percentage of internal infestation of wheat kernels and the number of insect fragments produced in the flour is complex and may be influenced by several factors, such as the insect species infesting the grain and whether they are alive or dead, the type of wheat, the type of sieve used, and the milling process itself (Harris et al. 1952, Sachdeva 1978). Preemergent adult insects are likely to produce more insect fragments in flour than the immature stages; however, this relationship has been poorly studied, and only Sachdeva (1978) reported that wheat infested with granary weevil adults produced $3 \mathrm{x}$ more fragments than wheat infested with weevil larvae.

The current standard method used by the FDA for detection of insect fragments (AOAC 1996) is very labor-intensive and expensive because it involves milling, extracting, and microscopically examining the number of insect fragments produced (Glaze and Bryce 1994). Thus, development of a fast and reliable alternative method is needed by the milling industry.

In a previous study, we found that a diode-array near-infrared (NIR) spectrometer with a spectral range of $400-1,700 \mathrm{~nm}$ was able to predict accurately whether flour samples contained less than or $>130$ insect fragments (Perez-Mendoza et al. 2003). Although that study had limited success detecting insect fragments below the FDA defect action level, NIR spectrometers with extended wavelength regions and higher sensitivity ranges are now available and may improve detection accuracy. In this study, we reexamined this method with instruments that extend the near infrared region tested to $2500 \mathrm{~nm}$.

The objectives of this study were to 1) characterize the relationship between different levels of internal wheat infestation with larvae, pupae, or preemergent adults of $R$. dominica and the number of insect fragments produced in the flour milled from that wheat; 2 ) to develop regression models to predict the maximum level of internal infestation for each insect stage that can be accepted by millers to produce flour with numbers of insect fragments below the FDA defect action level; and 3) compare the accuracy of three NIR spectrometers for determining number of insect fragments in the flour produced from the infested wheat.

\section{Materials and Methods}

Insect Cultures. Whole kernels infested with lesser grain borers were obtained from a laboratory strain reared on whole kernel, hard red winter wheat, Triticum aestivum L. (2002 crop). Insect cultures were started by placing 200 unsexed adults into $200 \mathrm{~g}$ of wheat, adjusted to $13.5 \%$ moisture content by adding distilled water as needed, in 800-ml glass jars capped with screen/filter paper lids. Jars were held in a rearing chamber at $30 \pm 1{ }^{\circ} \mathrm{C}$ and $70 \pm 5 \% \mathrm{RH}$ with a photoperiod of 12:12 (L:D) h. All founding adults were removed by sieving after $7 \mathrm{~d}$. After $21 \mathrm{~d}$, kernels containing larvae, pupae, or preemergent adults were detected by x-ray analysis (Throne 1994). Infested wheat kernels containing each insect stage were placed in aluminum dishes that were placed in a mechanical convection oven (Precision Scientific Inc. Chicago, IL) maintained at $130^{\circ} \mathrm{C}$ for $30 \mathrm{~min}$ to kill the insects. After cooling at room temperature, the desired number of infested kernels with each life stage was added to batches of uninfested wheat to complete 100 -g samples. Samples were conditioned to $15 \%$ moisture content for $1 \mathrm{wk}$ before milling.

Levels of Insect Infestation. Ten levels of grain infestation were tested to determine the fragment contribution of each stage of insect development (Table 1 ). The level of infestation was adjusted according to the insect stage and the expected fragment contribution based on a preliminary study (data not shown). The infestation levels used produced flour samples with fragment counts below and above the FDA defect action level.

Milling. Individual wheat samples $(100 \mathrm{~g})$ were milled on an experimental Bradender Quadrumat Sr. mill (type 12-10-N87, C.W. Brabender Instruments, Hackensack, NJ) at the USDA-ARS Grain Marketing and Production Research Center, Hard Winter Wheat Quality Laboratory, Manhattan, KS. Temperature of the rolls was maintained at $31.1-32.2^{\circ} \mathrm{C}$ during milling. The milling efficiency (percentage of flour yield) of 
this mill was $\approx 60 \%$. Therefore, milling produced flour samples of $\approx 60 \mathrm{~g}$ each.

Determination of Insect Fragments by Using the Standard Flotation Method. The current standard flotation method used by the FDA (AOAC 1996) was used to determine the number of fragments produced in the flour samples. This method was scaled up to collect insect fragments in $60 \pm 5 \mathrm{~g}$ of flour samples (Perez-Mendoza et al. 2003). Fragments in five replicates of each infestation level for each insect stage were determined.

Detection of Insect Fragments by Using NIRS. Three near-infrared spectrometers were used to collect spectral data from wheat flour samples containing varying levels of insect infestation: 1) Perten Diode Array (DA) 7000 (Perten Instruments Inc., Springfield, IL), 2) Cognis-QTA Bruker Optics FT-NIR (Cognis, Cincinnati, OH), and 3) Foss NIRSystems 6500 (Foss NIRSystems, Silver Spring, MD).

Perten Diode Array 7000. The DA 7000 is able to collect absorbance spectra over a range of 400-1690 $\mathrm{nm}$. This spectrometer uses both silicon ( $\mathrm{Si}$ ) and indium-gallium-arsenide (InGaAs) photodiodes with a high-intensity tungsten halogen lamp. Each entire flour sample was poured into a 12.5-cm-diameter sample ring above the 125-mm fixed sample viewing area at room conditions. The thickness of the flour sample was $\approx 1.2 \mathrm{~cm}$. The light beam comes from below the sample viewing area and penetrates the flour sample. Each spectrum saved was an average of 15 spectra collected in $\approx 3 \mathrm{~s}$.

Cognis-QTA FT-NIR. The QTA system is based on Bruker Optics's MATRIX Fourier Transform Near Infrared (FT-NIR) interferometer. A PbS detector was used to collect spectra in the $12,000-4,000-\mathrm{cm}^{-1}$ (830-2500-nm) wavelength range every $8 \mathrm{~cm}^{-1}$. Entire flour samples were placed directly in the rotating cup. Two replicates were collected for each flour sample. The instrument was set to automatically average the spectra of 100 scans into one spectrum for each sample being scanned. Before development of the calibration model, the resulting spectra from the two replicates of each sample were averaged, yielding one spectrum that represented that specific sample.

Foss NIR Systems 6500. The Foss NIR Systems 6500 scanning monochromator is able to collect spectra from 400 to $1098 \mathrm{~nm}$ (visible to short-wave NIR regions) with a silicon detector and from 1,100 to 2,500 $\mathrm{nm}$ (NIR region) with a $\mathrm{PbS}$ detector. The instrument comes equipped with a sample transport device that allows the sample in the quarter cup to be moved vertically past the light source. Flour samples were poured and leveled in a quarter cup and secured flush by using a white board material before placing the sample in the transport device. Each sample was scanned 64 times for the entire wavelength region and saved as a single spectrum.

Statistical Analysis. Equations describing the relationship between infestation level and the number of insect fragments produced in flour recovered with the standard flotation method were fit to the data using TableCurve 2D (SYSTAT Software Inc. 2002). Selec- tion of an equation to describe the data was based on the magnitude and the pattern of residuals, lack-of-fit tests, and $r^{2}$ values (Draper and Smith 1981). We also ensured that the shape of the curve was reasonable for describing the data. We used $95 \%$ prediction limits of the fitted equations to determine the maximum number of infested kernels that could be milled and still be below the FDA defect action level; this was determined as the lowest number of infested kernels whose upper $95 \%$ prediction limit was below 90 fragments in $60 \mathrm{~g}$ of flour (=75 fragments in $50 \mathrm{~g}$ flour).

NIR spectra were analyzed by partial least squares (PLS) regression (Martens and Naes 1989) by using PLSPlus/IQ software (Galactic Industries 2003). The coefficient of determination $\left(r^{2}\right)$, standard error of cross-validation (SECV), and beta coefficients were used to evaluate the potential of the NIRS technique. The SECV was used to determine the "best" number of independent variables in building a calibration equation. Beta coefficients indicated the wavelengths (positive and negative peaks in the plot) that are more heavily weighted. For any given wavelength, the absolute value of the beta coefficient indicates how important that wavelength was for classification. Thus, beta coefficient plots can be compared with NIR absorption spectra of specific flour and insect fragment components, such as protein, starch, lipids, or chitin to indicate which components cause unique NIR absorptions between flour samples with and without insect fragments (Dowell 2000). An insect fragment prediction is obtained by multiplying the absorbance at each wavelength by the corresponding beta coefficient and then summing each of those products across all wavelengths. Thus, the beta coefficients represent the calibration model. The optimum number of factors used for each model was determined by combined examinations of the prediction residual error sum of squares (PRESS) plot, $r^{2}$, SECV, and beta coefficient plot, which were all generated by the PLSPlus / IQ software.

Calibration models for each insect stage infesting the grain (larvae, pupae, or preemergent adults) and for each NIR spectrometer were developed using PLS (nine individual models). Five test samples of each insect-stage infestation level were scanned $(n=150)$. Finally, a calibration model that included combined data from the three insect stages (larvae + pupae + adults) was developed. Cross-validation was applied to optimize calibration models and detection of outliers by using PLSPlus/IQ software (Galactic Industries 2003). Outliers were excluded from final calibration models. Cross-validation attempts to predict unknown samples by using the training data set itself. To do this, one sample was removed from the data set, and a calibration was developed with the rest of the samples. Then, the removed sample was predicted. This was repeated for all samples.

The relationship between NIRS-predicted number of insect fragments and actual number of fragments in the flour samples (as estimated by the flotation method) was determined by using TableCurve 2D (SYSTAT Software Inc. 2002). Selection of an equation to describe the data was as described for infes- 
tation levels versus actual fragment counts. We used inverse prediction to estimate the actual number of fragments in a sample based on NIRS estimates, including 95\% CL on the estimates. We used these confidence limits from the inverse predictions to determine the maximum number of fragments that could be present in flour based on NIRS predictions and still be below the FDA defect action level; this was determined to be the lowest number of actual fragments whose upper $95 \%$ confidence limit was below 90 fragments in $60 \mathrm{~g}$ of flour (=75 fragments in $50 \mathrm{~g}$ flour).

\section{Results}

Effects of Insect Infestation Level on Fragment Counts. Fragments Contributed by Larvae. Larvae produced the lowest fragment counts as determined with the standard flotation method (Table 1). The predicted number of insect fragments produced by a single wheat kernel infested with one larva was 0.6 $[95 \% \mathrm{CL}=0.23-0.93$; $95 \%$ prediction limits $(\mathrm{PL})=$ $0-27.2]$. The number of insect fragments increased with increasing infestation levels. This relationship was described by the equation (SEs in parentheses):

$$
y=0.5775( \pm 0.175) * x^{1.126( \pm 0.0627)}
$$

where $y$ is number of fragments and $x$ is number of infested kernels $\left(r^{2}=0.95\right)$ (Fig. 1A). Based on the 95\% prediction limits for this equation, the maximum number of infested wheat kernels with larvae that millers can accept to produce flour that meets the FDA defect action level is 64 infested kernels in $100 \mathrm{~g}$ of wheat $(\approx 1.5 \%$ infested kernels) $(95 \%$ PL $=35.3-$ 89.8 fragments in $60 \mathrm{~g}$ of flour). Although a linear equation also described this relationship without significant lack of fit, we used a nonlinear equation to describe the data because of a better residual pattern.

Fragments Contributed by Pupae. Fragment counts in flour prepared from wheat samples infested with different numbers of kernels infested with pupae were intermediate between those produced by wheat samples infested with larvae or adults (Table 1). The predicted number of insect fragments produced from a single wheat kernel infested with one pupa was 1.6 (95\% CL $=0.90-2.4 ; 95 \% \mathrm{PL}=0-22.1)$. The relationship between the number of kernels infested with pupae and the number of insect fragments produced in flour was described by the following equation:

$$
y=1.646( \pm 0.372) * x^{1.025( \pm 0.0568)}
$$

where $y$ is number of fragments and $x$ is number of infested kernels $\left(r^{2}=0.95\right)$ (Fig. 1B). Based on the 95\% prediction limits for this equation, the maximum number of infested wheat kernels with pupae that millers can accept to produce flour that meets the FDA defect action level is 38 infested kernels in $100 \mathrm{~g}$ of wheat $(\approx 0.95 \%$ infested kernels) $(95 \% \mathrm{PL}=47.7$ 89.2 fragments in $60 \mathrm{~g}$ of flour). Although a linear equation also described this relationship without significant lack of fit, we used a nonlinear equation to describe the data because of a better residual pattern.
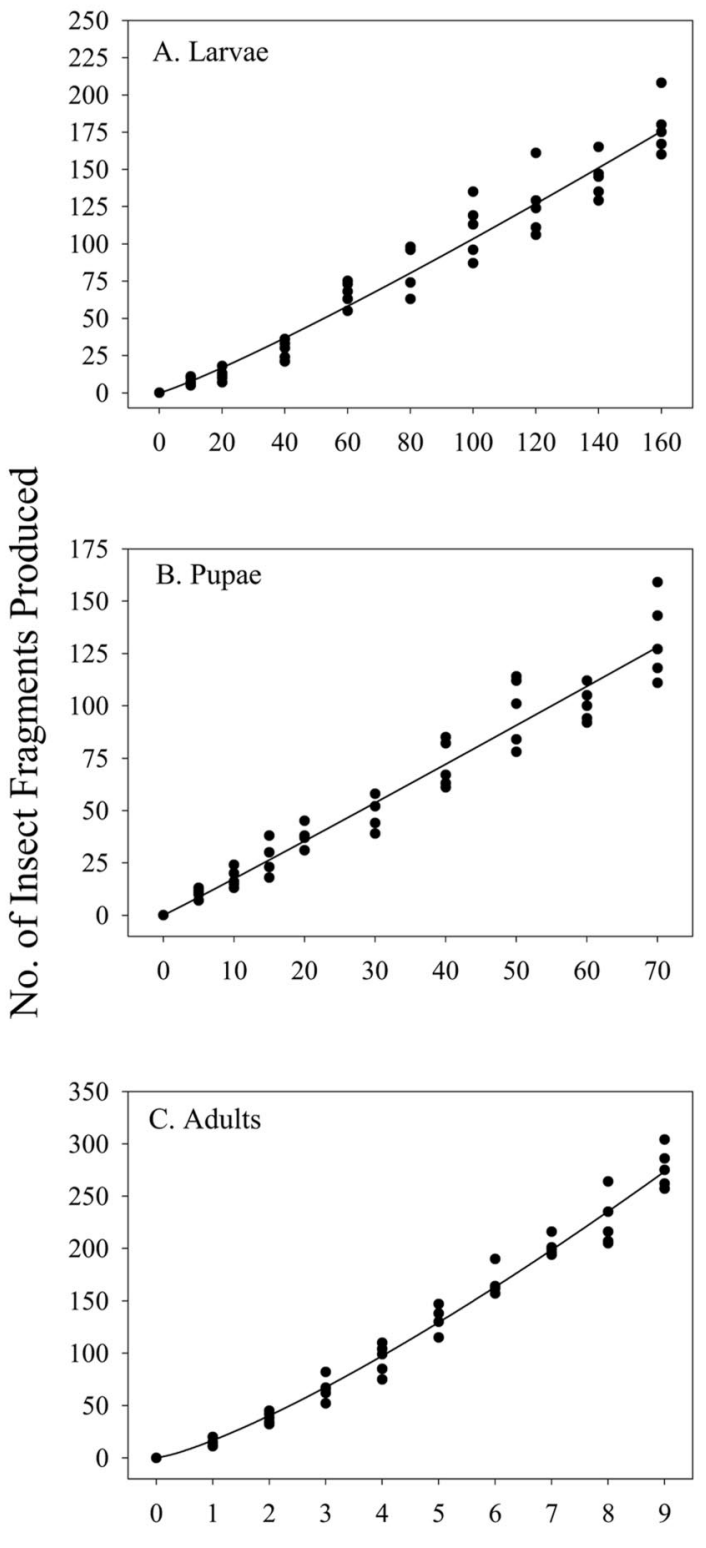

No. of Infested Kernels / $100 \mathrm{~g}$

Fig. 1. Relationship between number of infested kernels/ $100 \mathrm{~g}$ of wheat with larvae (A), pupae (B), and preemergent adults $(\mathrm{C})$, and number of insect fragments detected in milled flour samples by using the standard flotation method. Solid lines are from equations 1,2 , and 3.

Fragments Contributed by Preemergent Adults. Fragment counts for flour prepared from wheat samples infested with different numbers of kernels infested with preemergent adults were the highest compared with those produced in wheat samples infested with larvae or pupae (Table 1). The mean number of insect fragments produced by an individual infested wheat kernel containing one adult was $14.0 \pm 1.6$ (predicted number of insect fragments $=16.7 ; 95 \%$ 
Table 2. Equations describing the relationship between the number of insect fragments present in flour and the number of insect fragments predicted by using NIRS

\begin{tabular}{|c|c|c|c|c|c|c|c|}
\hline \multirow{2}{*}{$\begin{array}{c}\text { NIR } \\
\text { spectrometer }\end{array}$} & \multirow{2}{*}{ Stage } & \multirow{2}{*}{$\begin{array}{l}\text { Wavelength } \\
\text { range used in } \\
\text { model }(\mathrm{nm})\end{array}$} & \multirow{2}{*}{$\mathrm{SECV}^{a}$} & \multirow{2}{*}{$n$} & \multicolumn{3}{|c|}{ Equation parameters ${ }^{b}$} \\
\hline & & & & & $\mathrm{a} \pm \mathrm{SE}$ & $\mathrm{b} \pm \mathrm{SE}$ & $r^{2}$ \\
\hline \multirow{4}{*}{ Cognis-QTA } & Larvae & $1,055-2,500$ & 18.9 & 47 & $12.54 \pm 3.97$ & $0.8684 \pm 0.0402$ & 0.91 \\
\hline & Pupae & & 13.9 & 48 & $5.644 \pm 3.26$ & $0.9087 \pm 0.0487$ & 0.88 \\
\hline & Adults & & 26.6 & 50 & $13.73 \pm 5.84$ & $0.9016 \pm 0.0384$ & 0.92 \\
\hline & Larvae + pupae + adults & & 26.2 & 146 & $14.10 \pm 2.84$ & $0.8478 \pm 0.0261$ & 0.88 \\
\hline \multirow{4}{*}{ Perten 7000} & Larvae & $550-1,700$ & 16.5 & 48 & $6.152 \pm 3.82$ & $0.9224 \pm 0.0387$ & 0.93 \\
\hline & Pupae & & 17.4 & 46 & $7.514 \pm 4.15$ & $0.8649 \pm 0.0612$ & 0.82 \\
\hline & Adults & & 26.8 & 49 & $9.722 \pm 6.40$ & $0.9241 \pm 0.0417$ & 0.91 \\
\hline & Larvae + pupae + adults & & 34.9 & 141 & $14.25 \pm 3.78$ & $0.8171 \pm 0.0348$ & 0.80 \\
\hline \multirow[t]{4}{*}{ Foss 6500} & Larvae & $650-2,250$ & 21.7 & 46 & $11.47 \pm 5.01$ & $0.8818 \pm 0.0497$ & 0.88 \\
\hline & Pupae & & 17.0 & 48 & $7.881 \pm 3.74$ & $0.8473 \pm 0.0571$ & 0.83 \\
\hline & Adults & & 44.8 & 48 & $31.29 \pm 9.52$ & $0.7742 \pm 0.0622$ & 0.77 \\
\hline & Larvae + pupae + adults & & 58.3 & 145 & $51.22 \pm 4.87$ & $0.3933 \pm 0.0438$ & 0.36 \\
\hline
\end{tabular}

${ }^{a}$ Standard error of cross validation.

${ }^{b}$ Relationship is $y=\mathrm{a}+\mathrm{b} x$, where $y$ is NIRS-predicted number of fragments, $x$ is actual number of fragments, and $r^{2}$ is the percentage of variation in $y$ accounted for by using a linear model.

$\mathrm{CL}=13.8-19.6 ; 95 \%$ PL $=0-42.8)$. The relationship between the levels of internal wheat infestation with adults and the number of insect fragments produced in flour was described by the following equation:

$$
y=16.69( \pm 1.43) * x^{1.273( \pm 0.0430)}
$$

where $y$ is number of fragments and $x$ is number of infested kernels $\left(r^{2}=0.98\right)$ (Fig. 1C). Based on the 95\% prediction limits for this equation, the maximum number of wheat kernels infested by newly eclosed adults that millers can accept to produce flour that meets the FDA defect action level is two infested kernels in $100 \mathrm{~g}$ of wheat $(\approx 0.05 \%$ infested kernels $)$ $(95 \% \mathrm{PL}=14.0-66.7$ fragments in $60 \mathrm{~g}$ of flour). A linear equation was not appropriate for these data because of significant lack of fit.

Prediction of Insect Fragments in Flour by NIRS. Cognis-QTA FT-NIR. NIR spectra generated with this spectrometer correlated strongly with the actual number of insect fragments present in flour samples produced from wheat infested with larvae, pupae, or newly eclosed adults of the lesser grain borer (Table 2; Fig. 2). The range of $r^{2}$ was $0.88-0.92$ for the four models. Based on inverse predictions, a 60 -g flour sample that had a maximum of $56,59,44$, or 45 insect fragments based on NIRS predictions for larvae, pupae, preemergent adults, or all stages combined, respectively, would be below the FDA defect action level of 75 fragments in $50 \mathrm{~g}$ flour (upper $95 \%$ confidence limit would be below 90 fragments in $60 \mathrm{~g}$ flour). Samples with 125, 116, 145, or 136 insect fragments or more based on NIRS predictions for larvae, pupae, preemergent adults, or all stages combined, respectively, would be above the FDA defect action level of 75 fragments in $50 \mathrm{~g}$ flour (lower $95 \%$ confidence limit would be above 90 fragments in $60 \mathrm{~g}$ flour). It follows that one would not be able to determine whether the number of insect fragments in a sample was above or below the action level when NIRS predicts 57-124, $60-115,45-144$, or 46-135 insect fragments in samples containing larvae, pupae, preemergent adults, or all stages combined, respectively.
Perten Diode Array 7000. NIR spectra generated with this spectrometer correlated well with the actual number of insect fragments present in flour samples (Table 2; Fig. 3). The range of $r^{2}$ was $0.80-0.93$ for the four models. Based on inverse predictions, a 60 -g flour sample that had a maximum of $56,51,39$, or 29 insect fragments based on NIRS predictions for larvae, pupae, preemergent adults, or all stages combined, respectively, would be below the FDA defect action level of 75 fragments in $50 \mathrm{~g}$ flour (upper $95 \%$ confidence limit would be below 90 fragments in $60 \mathrm{~g}$ flour). Samples with 122, 121, 147 or 147 insect fragments or more based on NIRS predictions for larvae, pupae, preemergent adults, or all stages combined, respectively, would be above the FDA defect action level of 75 fragments in $50 \mathrm{~g}$ flour (lower $95 \%$ confidence limit would be above 90 fragments in $60 \mathrm{~g}$ flour). It follows that one would not be able to determine whether the number of insect fragments in a sample was above or below the action level when NIRS predicts 57-121, $52-120,40-146$, or 30-146 insect fragments in samples containing larvae, pupae, preemergent adults, or all stages combined, respectively.

Foss NIR Systems 6500. NIR spectra generated with this spectrometer correlated well with the actual number of insect fragments present in the flour samples (Table 2; Fig. 4). The range of $r^{2}$ was $0.36-0.88$ for the four models (Table 2). Based on inverse predictions, a 60 -g flour sample that had a maximum of 49,51, 19, or 8 insect fragments based on NIRS predictions for larvae, pupae, preemergent adults, or all stages combined, respectively, would be below the FDA defect action level of 75 fragments in $50 \mathrm{~g}$ flour (upper 95\% confidence limit would be below 90 fragments in $60 \mathrm{~g}$ flour). Samples with 132, 119, 181, or 165 insect fragments or more based on NIRS predictions for larvae, pupae, preemergent adults, or all stages combined, respectively, would be above the FDA defect action level of 75 fragments in $50 \mathrm{~g}$ flour (lower 95\% confidence limit would be above 90 fragments in $60 \mathrm{~g}$ flour). It follows that one would not be able to determine whether the number of insect fragments in a sample 

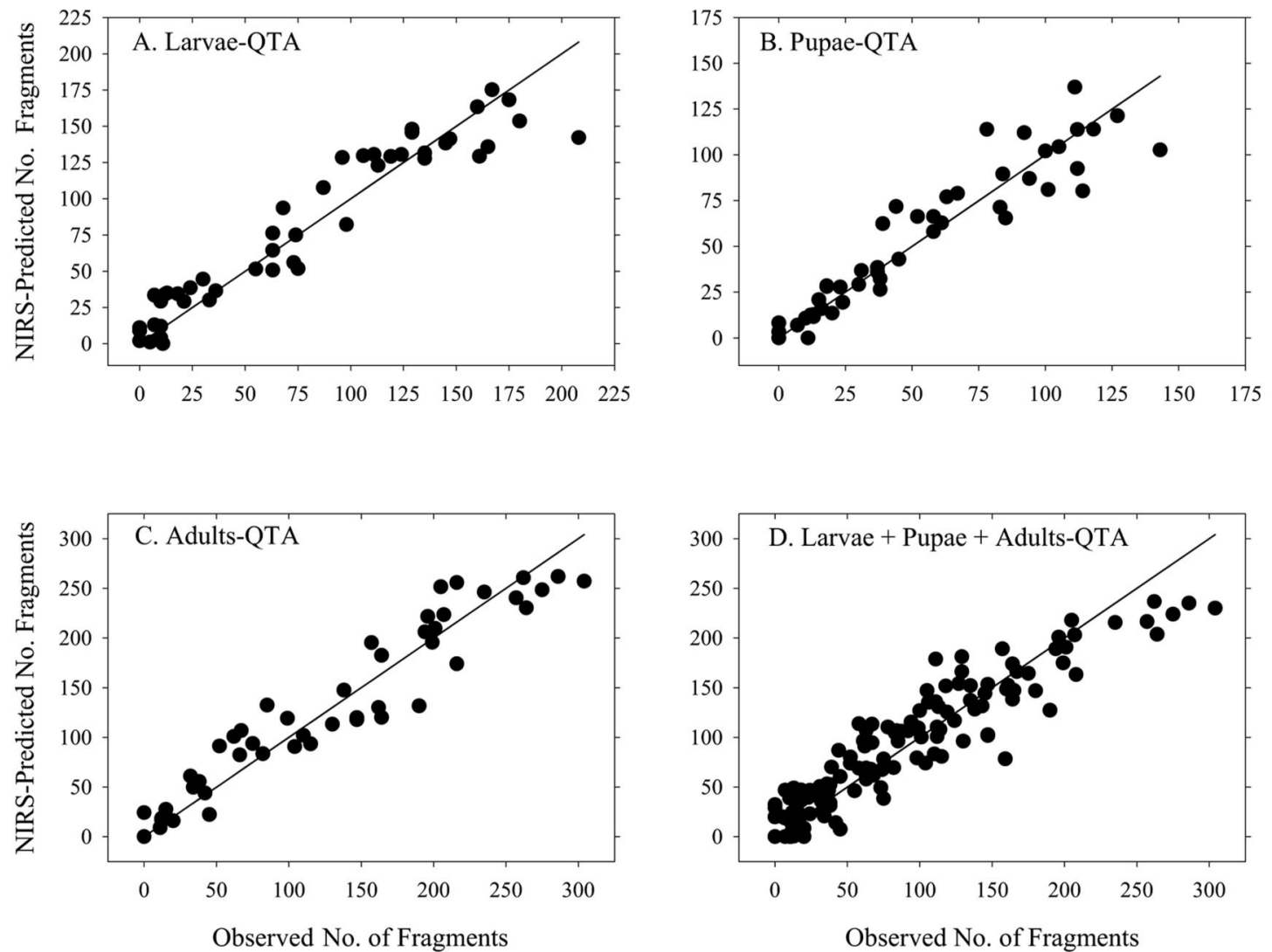

Fig. 2. Relationship between NIRS-predicted and observed number of insect fragments in flour samples produced from wheat infested with larvae (A), pupae (B), preemergent adults (C), and the three life stages combined (D). Calibration models generated with the Cognis-QTA NIR-instrument. Reference line shows perfect correlation.

was above or below the action level when NIRS predicts $50-131,52-118,20-180$, or 9-164 insect fragments in samples containing larvae, pupae, preemergent adults, or all stages combined, respectively.

Wavelength Regions of Interest. Beta coefficients obtained with the QTA spectrometer were most straightforward to interpret (Fig. 5). The wavelengths responsible for the ability to detect insect fragments in wheat flour by using NIRS may correspond to the first and second $\mathrm{CH}$ absorption overtones of $\mathrm{CH}, \mathrm{CH}_{2}$, and $\mathrm{CH}_{3}$ groups and the first combination $\mathrm{CH}$ absorption overtones $(1,140,1,180,1,360,1,446,1,665,1,730$, and $2,283 \mathrm{~nm})$, the first and second $\mathrm{OH}$ absorption overtones $(1,840,1,905$, and 2,380 $\mathrm{nm})$, and the second $\mathrm{NH}$ absorption overtones (2,061 and 2,240 nm) (Murray and Williams 1990, Shenk et al. 1992, Osborne et al. 1993).

\section{Discussion}

Wheat kernels infested with a single preemergent adult contributed $\approx 28$ and $10 \times$ as many fragments as wheat kernels infested with a single larva or pupa, respectively. This may be because the larval and pupal exoskeletons are weakly sclerotized, compared with the adult stage, and only the most heavily sclerotized structures of their bodies are able to resist the milling process or the hydrochloric acid used for the standard flotation method. Although we cannot identify the source of all the fragments found, the most common larval fragments found were the mandibles $(>75 \%$ of larval fragments), head capsule parts, and parts of the labrum and the epistoma. Sachdeva (1978) also found that $75-80 \%$ of the fragments observed in flour prepared from wheat infested with rice weevil larvae were mandibles and genae. In the flour samples prepared from wheat infested with pupae, the most common fragments observed were the mandibles, parts of the head capsule, eyes, antennae, and legs. The most common insect fragments observed in flour prepared from wheat infested with preemergent adults were the mandibles, portions of antennae, eyes, legs, labrum, labium, maxillae, furcae, and dorsal and ventral parts of the thorax and elytra. Gentry et al. (1991) also reported these parts of the body as the most common insect fragments in flour infested with lesser grain borer. Although we can detect the body part from which some fragments arise, FDA treats all fragments equally. 

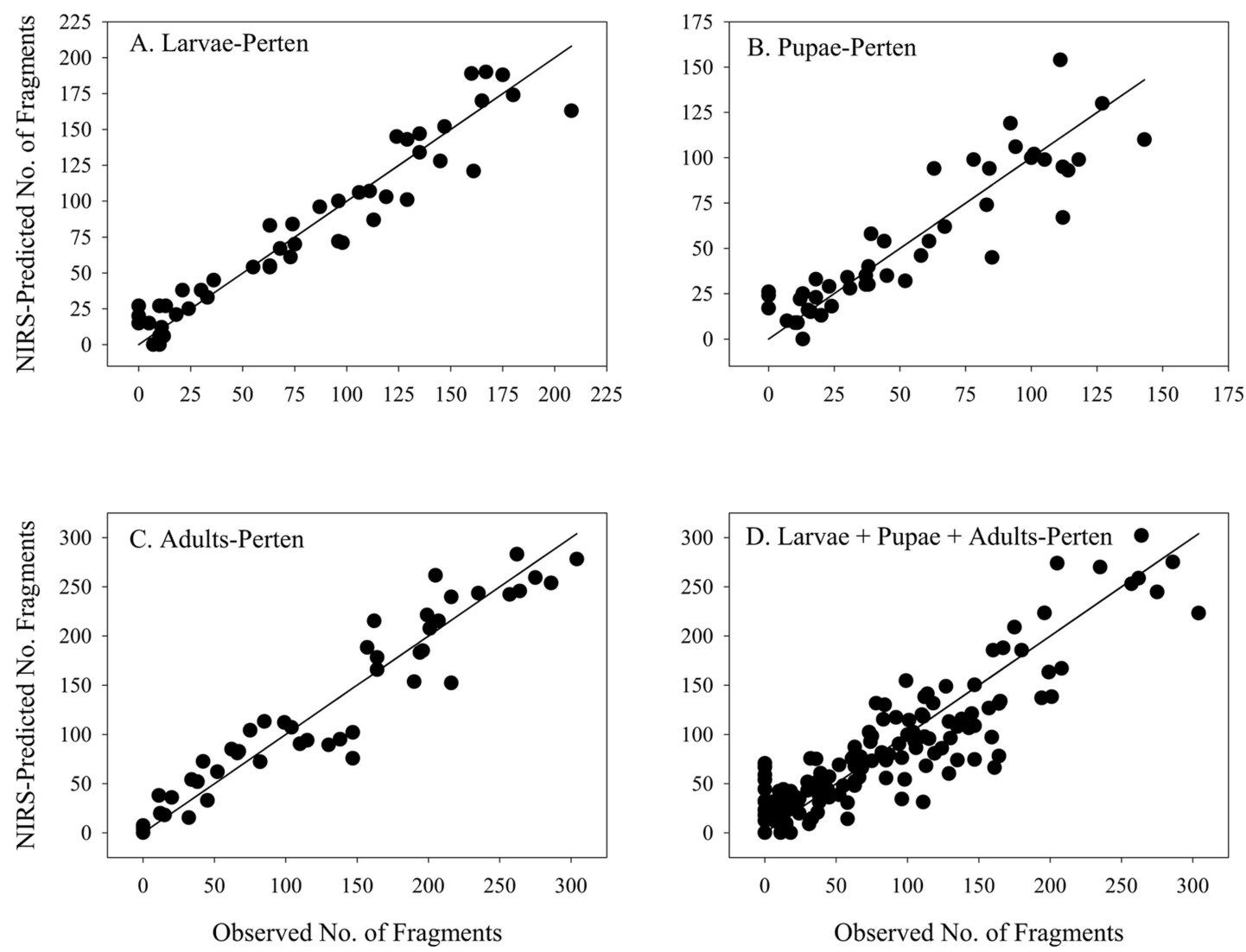

Fig. 3. Relationship between NIRS-predicted and observed number of insect fragments in flour samples produced from wheat infested with larvae (A), pupae (B), preemergent adults (C), and the three life stages combined (D). Calibration models generated with the Perten 7000 NIR-instrument. Reference line shows perfect correlation.

The number of insect fragments detected with the standard flotation method was directly proportional to the infestation level. Therefore, there was a strong correlation between the levels of internal wheat insect infestation and the number of fragments produced in flour; the same results were found by Harris et al. (1952) and Atui et al. (2002). Contrary to our results, Brader et al. (2002) found no strong correlation between the fragment counts and the level of infestation by late instar larvae of granary weevil, Sitophilus granarius (L.), perhaps because of their sampling protocol, which included subsampling. They infested batches of $250 \mathrm{~g}$ of wheat with 0-60 infested kernels and prepared subsamples of $50 \mathrm{~g}$, which they assumed would have homogeneous distributions of $0-12$ infested kernels. Russell (1988) showed that the insect distribution in subsamples taken from the same grain sample is not homogeneous. In the case of insect fragments, Brader et al. (2002) showed that both false positive and negative counts occurred in results from three laboratories with the standard flotation method. The standard flotation method requires highly trained technicians in microanalytical entomology to recognize insect fragments in flour (Kurtz and McCormack 1965).
We developed equations describing the relationships between the number of insect fragments produced and the level of insect infestation for each lesser grain borer life stage. These equations will be useful in predicting the maximum level of internal infestation that can be accepted by millers to produce flour with insect fragment counts below the FDA defect action level. Based on these equations, the maximum level of infestation that millers can accept in their grain is affected by the life stage of insects infesting the grain. If the grain is mainly infested with pupae and larvae, the level of allowable maximum infestation fluctuates from 0.95 to $1.5 \%$, respectively (380-640 infested kernels $/ \mathrm{kg}$ ). But when the grain is internally infested primarily with preemergent adults, the level of maximum infestation is reduced to less that $0.05 \%$ (20 infested kernels $/ \mathrm{kg}$ ). However, this last scenario is less likely to occur in the milling industry because kernels infested internally with pupae and preemergent adults are weak and are more easily broken open by using impact machines, and then exposed insects can be removed by screens or aspiration (Sachdeva 1978, Mills and Pedersen 1992, Brader 1997). However, kernels containing insects in the early stages of development may not be broken open by the impact machines 

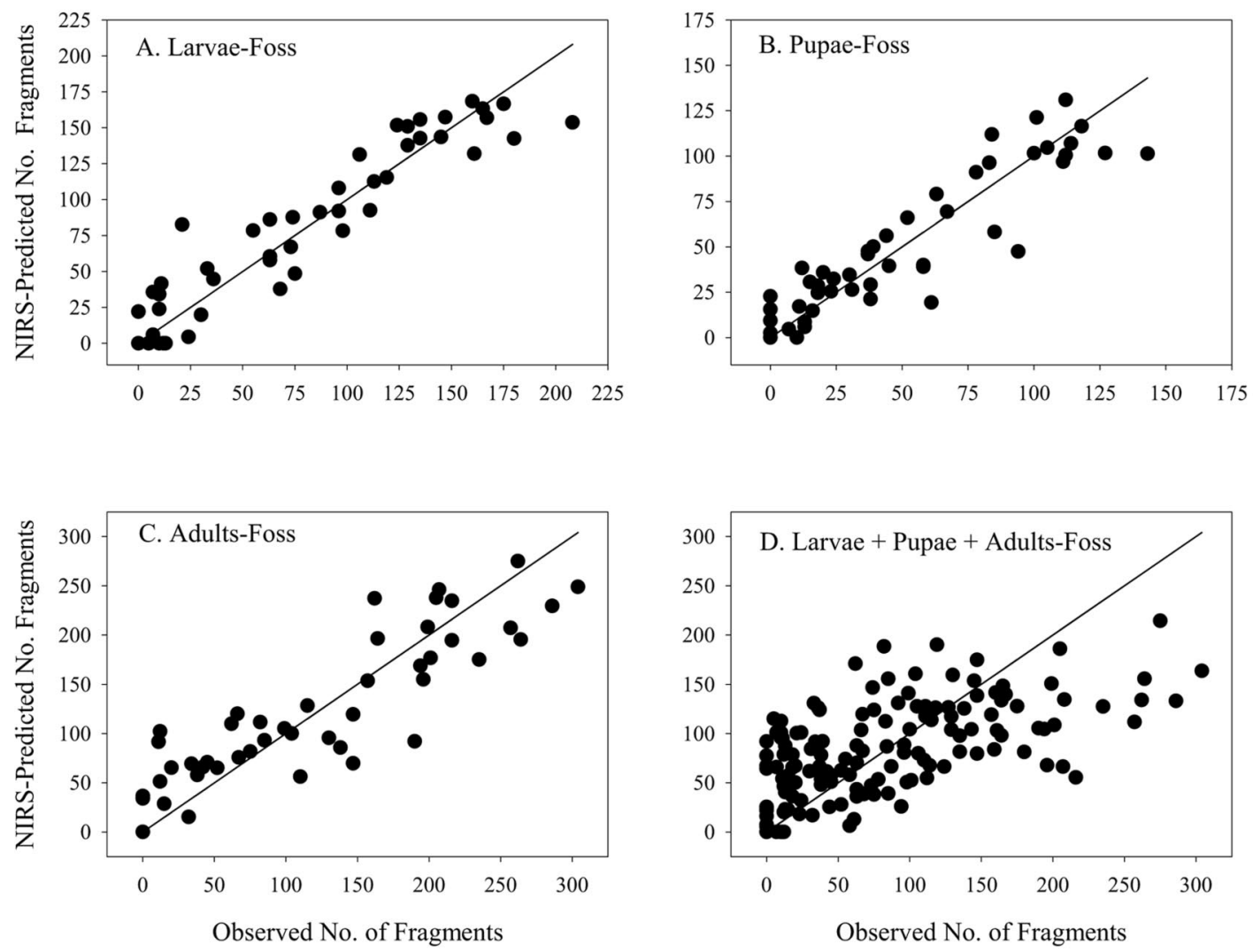

Fig. 4. Relationship between NIRS-predicted and observed number of insect fragments in flour samples produced from wheat infested with larvae (A), pupae (B), preemergent adults (C), and the three life stages combined (D). Calibration models generated with the Foss 6500 NIR-instrument. Reference line shows perfect correlation.

because they have not been sufficiently weakened by the insect (Sachdeva 1978, Mills and Pedersen 1992). As a result, several researchers have reported that most of the insect fragments present in flour are produced by the immature stages of the internal feeding insects. Our equations will be useful in sampling programs to determine how many insect fragments would be expected to be produced in flour milled from a sample of wheat, based on the number of internal insects of each stage detected in that sample of wheat.

NIR spectra generated using the three spectrometers were correlated with the actual number of insect fragments present in flour samples prepared from wheat infested with larvae, pupae, or preemergent adults. This indicates that NIRS is capable of predicting the degree of contamination by insect fragments in flour. The QTA spectrometer gave the best estimates of insect fragment levels in flour samples in our tests. For the model combining data for all life stages, the QTA spectrometer would not be able to determine whether fragment counts were above or below the defect action level when actual fragments in a 60-g sample were between 46 and 135; similar levels for the Perten and Foss spectrometers were 30-146 and 9-164. The QTA spectrometer may have yielded the best predictions of the number of fragments in samples compared with the calibration models generated with the other two spectrometers because the QTA spectrometer continuously mixed the flour sample while collecting spectra, whereas the other spectrometers sampled a static sample. In addition, the QTA and Perten spectrometers collect spectra for the whole sample, whereas the Foss spectrometer collects spectra for only a portion of the sample. Although the spectrometers are not highly accurate in determining number of insect fragments in flour samples, they provide results very quickly and could be used to screen a large number of flour samples. When the spectrometers indicate that either small numbers or large numbers of fragments are present, the standard flotation method would not need to be used. If the spectrometers are not able to determine whether the number of insect fragments is above or below the defect action level, then the standard flotation method could be used as a follow-up test.

Based on beta coefficients, absorbance regions (peaks) corresponding to $\mathrm{C}-\mathrm{H}, \mathrm{O}-\mathrm{H}$, and $\mathrm{N}-\mathrm{H}$ groups were the most important for NIRS detection of insect fragments in wheat flour (Murray and Williams 1990, Shenk et al. 1992, Osborne et al. 1993). Differences in absorption in the $\mathrm{C}-\mathrm{H}$ regions may be attributed to the presence of insect cuticle in the flour samples. Cuticle 

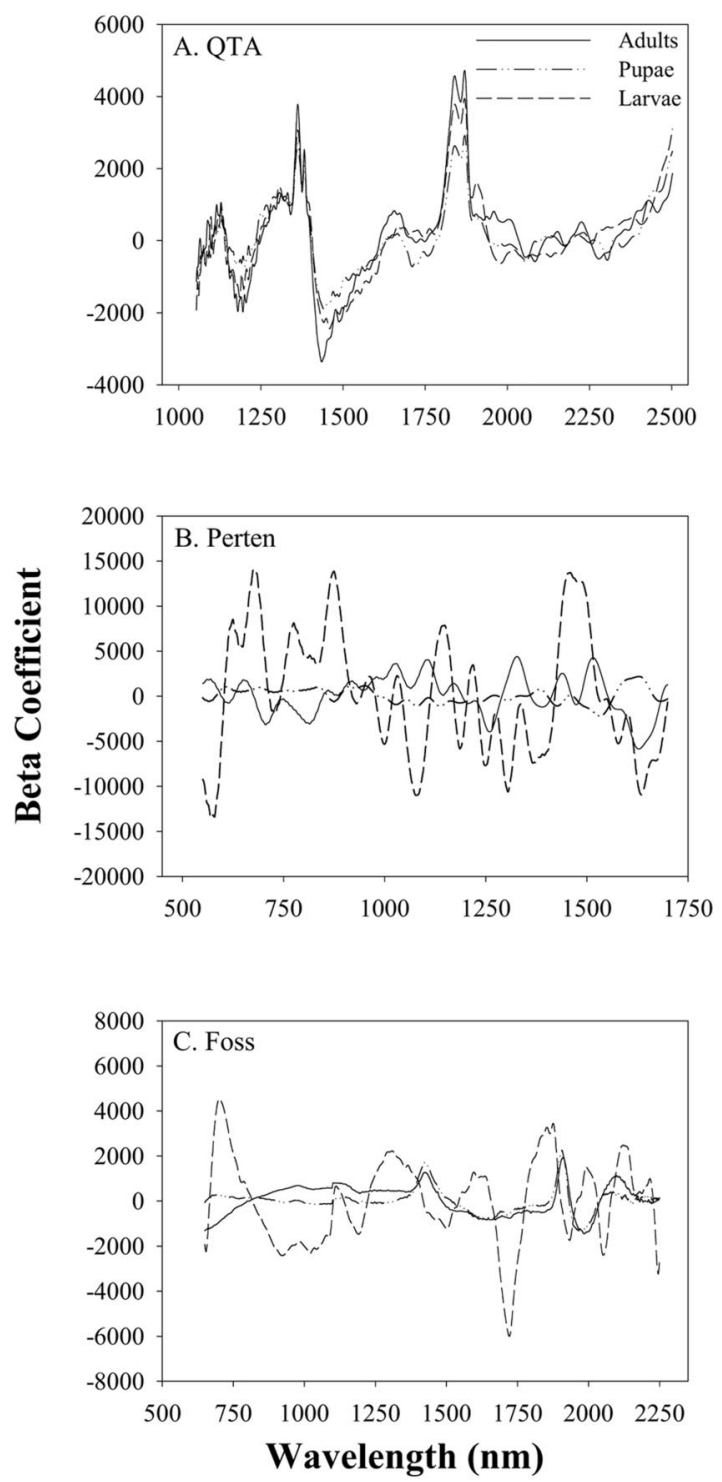

Fig. 5. Beta coefficients showing spectral wavelength bands used by partial least square calibrations to detect insect fragments in wheat flour with three different spectrometers.

contains both chitin and lipids, and several researchers have reported previously the influence of these components on the $\mathrm{C}-\mathrm{H}$ absorption region to detect the presence of insects inside wheat kernels (Ridgway and Chambers 1996; Ghaedian and Wehling 1997; Dowell et al. 1998, 1999; Maghirang et al. 2003). Differences in the wavelengths corresponding to $\mathrm{O}-\mathrm{H}$ regions might correspond to differences in starch and cellulose contents (Williams and Norris 1990, Shenk et al. 1992, Osborne et al. 1993) as a result of insect feeding damage to the kernels. Finally, differences in absorptions in the N-H regions most likely correspond to differences in protein content (Williams and Norris 1990), perhaps because of the protein content of the insect or digestion by the insect of proteins in the kernel. Therefore, the ability of NIRS to detect the presence of insect fragments in flour may primarily be because of differences in protein, lipids, and starch in flour samples as number of fragments changes.

Both the standard flotation method and the NIRS methods can detect and quantify the number of insect fragments produced by the lesser grain borer in wheat flour. The flotation method is more precise, but it is destructive, time-consuming, expensive, and requires highly trained technicians. In contrast, although NIRS is less precise, it is rapid, nondestructive, does not require extensive sample preparation, and could easily be automated for a more sophisticated sampling protocol for large flour bulks.

\section{Acknowledgments}

We thank Laura McLaughlin and the Grain Quality and Structure Research Unit (GMPRC) for milling the wheat samples, and Ann Redmon for excellent technical assistance. We gratefully acknowledge Perten Instruments, Cognis, and Foss NIRSystems for providing instrumentation for this study. We also thank Donghai Wang (Department of Agricultural Engineering, Kansas State University), Michael Toews (USDA-ARS-GMPRC), David K. Weaver (Department of Entomology, Montana State University), and Richard T. Arbogast (USDA-ARS-CMAVE) for comments and suggestions on an earlier version of the manuscript.

\section{References Cited}

[AOAC] Association of Official Analytical Chemists. 1996. 16.5.11 AOAC Official method 972.32, Light filth (preand post-milling) in flour (white), p. 18. In Official Methods of Analysis of AOAC International, 16th ed. AOAC International, Gaithersburg, MD.

Atui, M. B., S.M.N. Lazzari, F. A. Lazzari, and P. W. Flinn. 2002. Comparison of ELISA and fragment count methods for detection of insects in wheat flour, pp. 135-138. In P. E. Credland, D. M. Armitage, C. H. Bell, P. M. Cogan, and E. Highley [eds.], Proceedings of the 8th International Working Conference on Stored Product Protection, 22-26 July, 2002, York, United Kingdom. CAB International, Wallingford, United Kingdom.

Brader, B. 1997. Are food sanitation assays meaningful? Cereal Foods World 42: 759-760.

Brader, B., R. C. Lee, R. Plarre, W. Burkholder, G. B. Kitto, C. Kao, L. Polston, E. Dorneanu, I. Szabo, B. Mead, B. Rouse, D. Sullins, and R. Denning. 2002. A comparison of screening methods for insect contamination in wheat. J. Stored Prod. Res. 38: 75-86.

Dowell, F. E. 2000. Differentiating vitreous and nonvitreous durum wheat kernels by using near-infrared spectroscopy. Cereal Chem. 77: 155-158.

Dowell, F. E., J.E. Throne, and J. E. Baker. 1998. Automated nondestructive detection of internal insect infestation of wheat kernels by using near-infrared spectroscopy. J. Econ. Entomol. 91: 899-904.

Dowell, F. E., J. E. Throne, D. Wang, and J. E. Baker. 1999. Identifying stored-grain insects using near-infrared spectroscopy. J. Econ. Entomol. 92: 165-169.

Draper, N. R., and H. Smith. 1981. Applied regression analysis, 2nd ed. Wiley, New York.

Elek, J. A. 1994. Methods for collecting eggs and monitoring egg-hatch and immature development of Rhyzopertha 
dominica (F.) (Coleoptera: Bostrichidae). J. Stored Prod. Res. 30: 261-265.

[FDA] Food and Drug Administration. 1997. 578.450 Wheat flour -adulteration with insect fragments and rodent hairs (CPG 7104.06). Compliance policy guides manual, chapter 5, Foods, color and cosmetics, Sub chapter 578 -processed grain (http:/ / www.fda.gov/ora/ compliance_ref/cpg/default.htm\#1998).

[FGIS] Federal Grain Inspection Service. 1999. Official United States standards for grain subpart M: United States Standards for wheat (http:/ / www.usda.gov/gipsa/ reference-library/standards/810101.pdf).

Galactic Industries. 2003. Algorithms: partial least squares (http://www.galactic.com/ algorithms/pls.htm).

Gentry, J. W., K. L. Harris, and J. W. Gentry, Jr. 1991. Microanalytical entomology for food sanitation control. Association of Official Analytical Chemists, Melbourne, FL.

Ghaedian, A. R., and R. L. Wehling. 1997. Discrimination of sound and granary-weevil-larva-infested wheat kernels by near-infrared diffuse reflectance spectroscopy. J. AOAC Int. 80: 997-1005.

Glaze, L. E., and J. R. Bryce. 1994. Extraction of light filth from whole-wheat flour, flotation method: collaborative study. J. AOAC Int. 77: 1150-1152.

Hagstrum, D. W., and P. W. Flinn. 1994. Survival of Rhyzopertha dominica (Coleoptera: Bostrichidae) in stored wheat under fall and winter temperature conditions. Environ. Entomol. 23: 390-395.

Hagstrum, D. W., A. K. Dowdy, and G. E. Lippert. 1994. Early detection of insects in stored wheat using sticky traps in bin headspace and prediction of infestation level. Environ. Entomol. 23: 1241-1244.

Harris, K. L., J. F. Nicholson, L. K. Randolph, and J. L. Trawick. 1952. An investigation of insect and rodent contamination of wheat and wheat flour. J. AOAC 35: $115-157$.

Kurtz, O. L., and T. H. McCormack. 1965. Comparison of AACC and AOAC methods for extraneous materials in flour. J. AOAC 48: 554-558.

Maghirang, E. B., F. E. Dowell, J. E. Baker, and J. E. Throne. 2003. Automated detection of single wheat kernels containing live or dead insects using near-infrared reflectance spectroscopy. Trans. ASAE 46: 1277-1282.

Martens, H., and T. Naes. 1989. Multivariate calibration. Wiley, Chichester, United Kingdom.

Mills, R., and J. Pedersen. 1992. A flour mill sanitation manual. Eagan Press, St. Paul, MN.

Murray, I., and P. C. Williams. 1990. Chemical principles of near-infrared technology, pp. 17-34. In P. C. Williams and K. H. Norris [eds.], Near-infrared technology in the ag- ricultural and foods industries. American Association of Cereal Chemists, St. Paul, MN.

Osborne, B. G., T. Fearn, and P. H. Hindle. 1993. Practical NIR spectroscopy with applications in food and beverage analysis. Longman Scientific \& Technical, Harlow, United Kingdom.

Pedersen, J. 1992. Insects: Identification, damage, and detection. In D. B. Sauer [ed.], Storage of cereal grains and their products. American Association of Cereal Chemists, St. Paul, MN.

Perez-Mendoza, J., J. E. Throne, F. E. Dowell, and J. E. Baker. 2003. Detection of insect fragments in wheat flour by near-infrared spectroscopy. J. Stored. Prod. Res. 39: 305312 .

Perez-Mendoza, J., P. W. Flinn, J. F. Campbell, D. W. Hagstrum, and J. E. Throne. 2004. Detection of stored-grain insect infestation in wheat transported in railroad hopper-cars. J. Econ. Entomol. 97: 1474-1483.

Ridgway, C., and J. Chambers. 1996. Detection of external and internal insect infestation in wheat by near-infrared reflectance spectroscopy. J. Sci. Food Agric. 71: 251-264.

Russell, G. E. 1988. Evaluation of four analytical methods to detect weevils in wheat: granary weevil, Sitophilus granarius (L.), in soft white wheat. J. Food Protect. 51: 547-553.

Sachdeva, A. S. 1978. Effect of infestation stage, form and treatment on fragment count in flour. M.S. thesis, Kansas State University, Manhattan.

Shenk, J. S., J. J. Workman, Jr., and M. O. Westerhaus. 1992. Application of NIR spectroscopy to agricultural products, pp. 383-431. In D. A. Burns and E. W. Ciurczak [eds.], Handbook of near-infrared analysis. Marcel Decker, New York.

SYSTAT Software Inc. 2002. TableCurve 2D version 5.01. SYSTAT Software Inc., Richmond, CA.

Throne, J. E. 1994. Life history of immature maize weevils (Coleoptera: Curculionidae) on corn stored at constant temperatures and relative humidities in the laboratory. Environ. Entomol. 23: 1459-1471.

Williams, P. C., and K. H. Norris. 1990. Qualitative applications of near-infrared reflectance spectroscopy, pp. 241-288. In P. C. Williams and K. H. Norris [eds.], Nearinfrared technology in the agricultural and foods industries. American Association of Cereal Chemists, St. Paul, MN.

Wingfield, J., and J. Pedersen. 1985. Insect fragment levels in flour milled from selected commercial wheat blends. Bull. Assoc. Oper. Millers, April 1985.

Received 31 March 2005; accepted 20 August 2005. 